\title{
Safety and Prevention of Complications in Endoscopic Sedation
}

\author{
Chang Hwan Choi
}

Received: 15 March 2012/ Accepted: 30 April 2012/Published online: 22 May 2012

(C) Springer Science+Business Media, LLC 2012

The administration of sedatives during gastrointestinal (GI) endoscopy is considered a standard practice at many centers. Sedation during endoscopic procedures can improve patient comfort and practice efficiency, especially during therapeutic procedures [1]. However, sedation is a major contributor to complications during endoscopy [2-4]. Clinically insignificant complications, including transient hypotension, bradycardia, and microaspiration, can occur, but serious complications, such as sedation-induced death, neurologic sequelae, and aspiration pneumonia, may also occur.

Many sedative agents are used in endoscopy, and combinations of low-dose benzodiazepine with opiates are traditionally used to achieve moderate levels of sedation $[1,2,4]$. The incidence of adverse events for these standard sedatives is very low [2, 5-8]. For instance, a large-scale retrospective study (21,011 patients) of midazolam for endoscopic sedation showed that the complication rate was only $1.35 \%$ [2].

Over the past decade, propofol has become an increasingly popular agent for endoscopic sedation and has replaced standard sedation regimens largely because of its rapid onset and short duration of effect $[9,10]$. Although propofol is an attractive sedative for endoscopic procedures, its adverse effects are more serious than those of benzodiazepines used with or without opiates. Debate also continues regarding its safe administration by non-anesthesiologists. However, the safety and efficacy of propofol for routine endoscopic procedures when administered by endoscopists as well as

\section{H. Choi $(\bowtie)$}

Department of Internal Medicine, Chung-Ang University

College of Medicine, 224-1 Heukseok-dong,

Dongjak-gu, Seoul 156-755, Republic of Korea

e-mail: gicch@cau.ac.kr anesthesiologists have been reported in multiple trials [1113]. In addition, there are data supporting the safe use of propofol for advanced endoscopic procedures such as endoscopic retrograde cholangiopancreatography (ERCP) and/or endoscopic ultrasound (EUS) [14-19]. The incidences of complications, such as hypoxemia, bradycardia, and the need for airway intervention were not different between propofol and standard sedatives in previous studies.

Rex et al. [20] reported complication rates for a very large sample of patients $(646,080)$ who underwent endoscopist-directed propofol sedation, and found that endotracheal intubations, permanent neurologic injuries, and deaths only affected 11,0 , and four patients, respectively, while the proportion of cases requiring mask ventilation was a mere $0.1 \%$. The four deaths in this large cohort of patients occurred in patients with American Society of Anesthesiologists (ASA) [21] statuses of 3 or higher who were undergoing non-routine medical procedures, and three of the patients had serious underlying illnesses. These results indicate that the safety of propofol administration by endoscopists is comparable or superior to the published safety records of opioids and benzodiazepines administered by endoscopists for GI endoscopy [5-8]. The low incidence of complications may be attributed to new technologies such as computer-assisted personalized sedation. Additionally, high levels of monitoring may standardize the use of propofol by non-anesthesiologists in endoscopy [22-25]. The American College of Gastroenterology and the American Society for Gastrointestinal Endoscopy have published a joint statement supporting the safe use of non-anesthesiologist-administered propofol for GI endoscopy [26].

Even though the complication rates associated with the increasing use of propofol for endoscopic sedation are very low, it is important to identify patients and procedures at the highest risk of sedation-related complications. Several 
studies have suggested predictors of complications associated with endoscopic sedation. Cote et al. [27] reported the incidences of sedation-related complications associated with propofol use and their predictors during advanced endoscopic procedures, focusing on airway complications. The incidences of desaturation $(12.8 \%)$ and the need for airway modification $(14.4 \%)$ were relatively high, possibly due to the high proportion of patients $(60.5 \%)$ with ASA scores of 3 or higher and long endoscopy times in their sample. Male sex, high body mass index (BMI), and high ASA score were predictors of complications during sedation for endoscopy. Heuss et al. [28] described 3,475 endoscopic procedures in which propofol sedation was used, and documented an incidence of desaturation (1.6\%) that was similar to those in the other reports. They also found that ASA scores of 3 or higher were predictors of complications. An Italian study recently described a sample of 17,542 patients sedated by Monitored Anesthesia Care (MAC) during endoscopy and predicted the occurrence of any complication using six variables that were screened for age (1-year odds ratio [OR] 1.02), BMI (one-point OR 1.03), ASA score ("3-4" vs. "1-2" OR 1.69), Mallampati score [29] ("3-4" vs. "1-2" OR 1.33), emergent nature of the procedure (OR 1.48), and length of the procedure (OR 2.00). Occurrence of desaturation was predicted by four variables: age (1-year OR 1.02), BMI (one-point OR 1.12), ASA score ("3-4" vs. "1-2" OR 1.95), and duration of the procedure (1-min OR 1.01) [22].

In order to describe the incidences of complications associated with endoscopic sedation and its relationship to clinical factors and sedation level in more detail, Chafic et al. [30] performed a thorough prospective analysis of the incidences of cough, hemodynamic changes, and oxygen desaturation in patients undergoing various sedative regimens for GI endoscopy, and correlated the occurrences of these events with clinical factors, procedure type and duration, sedative agents, and sedation level. Although many previous studies examined measurements of hemodynamic changes during endoscopic procedures $[14,15$, 17, 27, 31-34], few have given detailed descriptions of quantitative changes in hemodynamic parameters and oxygen saturation during endoscopic sedation. There are also no reports regarding the frequency of cough during endoscopic procedures performed under sedation. Similar to previous studies, Chafic et al. found that the complication rates were very low. Thirteen percent of patients had at least one cough, and $3 \%$ had prolonged cough. The clinical predictors of cough during endoscopy with sedation, which potentially cause post-procedural pulmonary infections, are deeper levels of sedation, propofol use, longer procedures, hiccupping, and rotation into the supine position during colonoscopy. Oxygen desaturation was rare (4\%) and was associated only with deep sedation. Mean systolic and diastolic blood pressure (BP) dropped by 7.3 and $5.6 \%$, respectively. Decreases in systolic BP were more common during colonoscopy and in whites, males, nonsmokers, and patients receiving midazolam and fentanyl. Heart rate (HR) dropped $>20 \%$ from baseline in $15 \%$ of patients and was more common during colonoscopy. However, no patient required pharmacologic treatment of BP or HR. Although this study was not a randomized controlled study, its results provide guidance for situations during which increased vigilance is required to prevent complications, especially microaspiration that may be associated with post-procedural pulmonary infections. These data may be helpful for preventing procedure-related complications.

Further studies are needed to identify safer and more ideal methods of sedation for GI endoscopy. First, Chafic et al. [30] did not include many patients who underwent advanced endoscopic procedures such as ERCP, EUS, and endoscopic submucosal dissection (ESD) and did not assess the relationships between ASA scores and complication rates. High ASA scores and longer procedure times have been suggested to be important predictors of the occurrence of complications during sedation for endoscopy [22, 27, 28]. As Rex et al. [20] suggested, anesthesiologist-administered MAC may be preferred over gastroenterologist-administered sedation for patients with an ASA score higher than 2. Although nonanesthesiologists have successfully used propofol for patients with higher ASA classes in several reports [35], further studies to determine the safety of non-anesthesiologist-administered sedation for GI endoscopy in patients with high ASA scores or patients who require longer procedure times are still needed. Second, while many previous studies that assessed complication rates associated with endoscopic sedation dealt mainly with upper endoscopic procedures, Chafic et al. [30] included many patients who underwent colonoscopy. Colonoscopy patients were more likely to cough when they were rotated into the supine position and to develop drops in blood pressure and bradycardia with sedation. Additional studies to evaluate complication rates solely during colonoscopic sedation and the predictors of those complications would be informative. Third, previous studies, including Chafic et al. [30], did not track lateoccurring sedation complications such as pulmonary infections. Thus, more long-term follow-up studies are needed. Finally, to identify optimal methods for endoscopic sedation that are tailored to the clinical risks of individual patients as well as to type of endoscopic procedure, further identification of major clinical predictors of complications related to endoscopic sedation is necessary.

Although sedation for GI endoscopy is usually considered safe and major adverse events are rarely encountered, clinicians should still perform thorough risk assessments for individual patients and pay attention to the occurrence 
of complications. In addition, efforts to find the best method for endoscopic sedation should be continued, including optimal depth of sedation and the level of monitoring required for sedated patients, in addition to the development of new drugs and ideal drug delivery systems.

Conflict of interest None.

\section{References}

1. Muller M, Wehrmann T. How best to approach endoscopic sedation? Nat Rev Gastroenterol Hepatol. 2011;8:481-490.

2. Arrowsmith JB, Gerstman BB, Fleischer DE, Benjamin SB. Results from the American Society for Gastrointestinal Endoscopy/U.S. Food and Drug Administration collaborative study on complication rates and drug use during gastrointestinal endoscopy. Gastrointest Endosc. 1991;37:421-427.

3. Cohen LB, Wecsler JS, Gaetano JN, et al. Endoscopic sedation in the United States: results from a nationwide survey. Am J Gastroenterol. 2006;101:967-974.

4. Froehlich F, Thorens J, Schwizer W, et al. Sedation and analgesia for colonoscopy: patient tolerance, pain, and cardiorespiratory parameters. Gastrointest Endosc. 1997;45:1-9.

5. Daneshmend TK, Bell GD, Logan RF. Sedation for upper gastrointestinal endoscopy: results of a nationwide survey. Gut. 1991;32:12-15.

6. Froehlich F, Gonvers JJ, Fried M. Conscious sedation, clinically relevant complications and monitoring of endoscopy: results of a nationwide survey in Switzerland. Endoscopy. 1994;26:231-234.

7. Sharma VK, Nguyen CC, Crowell MD, Lieberman DA, de Garmo P, Fleischer DE. A national study of cardiopulmonary unplanned events after GI endoscopy. Gastrointest Endosc. 2007;66:27-34.

8. Thompson AM, Wright DJ, Murray W, Ritchie GL, Burton HD, Stonebridge PA. Analysis of 153 deaths after upper gastrointestinal endoscopy: room for improvement? Surg Endosc. 2004;18:22-25.

9. Faulx AL, Vela S, Das A, et al. The changing landscape of practice patterns regarding unsedated endoscopy and propofol use: a national Web survey. Gastrointest Endosc. 2005;62:9-15.

10. Mackenzie N, Grant IS. Propofol for intravenous sedation. Anaesthesia. 1987;42:3-6.

11. Clarke AC, Chiragakis L, Hillman LC, Kaye GL. Sedation for endoscopy: the safe use of propofol by general practitioner sedationists. Med J Aust. 2002;176:158-161.

12. Rex DK, Heuss LT, Walker JA, Qi R. Trained registered nurses/ endoscopy teams can administer propofol safely for endoscopy. Gastroenterology. 2005;129:1384-1391.

13. Tohda G, Higashi S, Wakahara S, Morikawa M, Sakumoto H, Kane T. Propofol sedation during endoscopic procedures: safe and effective administration by registered nurses supervised by endoscopists. Endoscopy. 2006;38:360-367.

14. Kongkam P, Rerknimitr R, Punyathavorn S, et al. Propofol infusion versus intermittent meperidine and midazolam injection for conscious sedation in ERCP. J Gastrointestin Liver Dis. 2008;17:291-297.

15. Paspatis GA, Manolaraki MM, Vardas E, Theodoropoulou A, Chlouverakis G. Deep sedation for endoscopic retrograde cholangiopancreatography: intravenous propofol alone versus intravenous propofol with oral midazolam premedication. Endoscopy. 2008;40:308-313.

16. Riphaus A, Stergiou N, Wehrmann T. Sedation with propofol for routine ERCP in high-risk octogenarians: a randomized, controlled study. Am J Gastroenterol. 2005;100:1957-1963.
17. Vargo JJ, Zuccaro G Jr, Dumot JA, et al. Gastroenterologistadministered propofol versus meperidine and midazolam for advanced upper endoscopy: a prospective, randomized trial. Gastroenterology. 2002;123:8-16.

18. Wehrmann T, Riphaus A. Sedation with propofol for interventional endoscopic procedures: a risk factor analysis. Scand $J$ Gastroenterol. 2008;43:368-374.

19. Yusoff IF, Raymond G, Sahai AV. Endoscopist administered propofol for upper-GI EUS is safe and effective: a prospective study in 500 patients. Gastrointest Endosc. 2004;60:356-360.

20. Rex DK, Deenadayalu VP, Eid E, et al. Endoscopist-directed administration of propofol: a worldwide safety experience. Gastroenterology. 2009;137:1229-1237.

21. Keats AS, The ASA. Classification of physical status-a recapitulation. Anesthesiology. 1978;49:233-236.

22. Agostoni M, Fanti L, Gemma M, Pasculli N, Beretta L, Testoni PA. Adverse events during monitored anesthesia care for GI endoscopy: an 8-year experience. Gastrointest Endosc. 2011;74:266-275.

23. Fanti L, Agostoni M, Arcidiacono PG, et al. Target-controlled infusion during monitored anesthesia care in patients undergoing EUS: propofol alone versus midazolam plus propofol. A prospective double-blind randomised controlled trial. Dig Liver Dis. 2007;39:81-86.

24. Fanti L, Agostoni M, Casati A, et al. Target-controlled propofol infusion during monitored anesthesia in patients undergoing ERCP. Gastrointest Endosc. 2004;60:361-366.

25. Pambianco DJ, Whitten CJ, Moerman A, Struys MM, Martin JF. An assessment of computer-assisted personalized sedation: a sedation delivery system to administer propofol for gastrointestinal endoscopy. Gastrointest Endosc. 2008;68:542-547.

26. Vargo JJ, Cohen LB, Rex DK, Kwo PY. Position statement: nonanesthesiologist administration of propofol for GI endoscopy. Gastroenterology. 2009;137:2161-2167.

27. Cote GA, Hovis RM, Ansstas MA, et al. Incidence of sedationrelated complications with propofol use during advanced endoscopic procedures. Clin Gastroenterol Hepatol. 2010;8:137-142.

28. Heuss LT, Schnieper P, Drewe J, Pflimlin E, Beglinger C. Risk stratification and safe administration of propofol by registered nurses supervised by the gastroenterologist: a prospective observational study of more than 2000 cases. Gastrointest Endosc. 2003;57:664-671.

29. Mallampati SR, Gatt SP, Gugino LD, et al. A clinical sign to predict difficult tracheal intubation: a prospective study. Can Anaesth Soc J. 1985;32:429-434.

30. El Chafic AH, Eckert G, Rex DK. Prospective description of coughing, hemodynamic changes, and oxygen desaturation during endoscopic sedation. Dig Dis Sci. 2012. (Epub ahead of print). doi: 10.1007/s10620-012-2057-z.

31. Baudet JS, Diaz-Bethencourt D, Aviles J, Aguirre-Jaime A. Minor adverse events of colonoscopy on ambulatory patients: the impact of moderate sedation. Eur J Gastroenterol Hepatol. 2009;21:656-661.

32. Rex DK, Overley C, Kinser K, et al. Safety of propofol administered by registered nurses with gastroenterologist supervision in 2000 endoscopic cases. Am J Gastroenterol. 2002;97:1159-1163.

33. Seifert H, Schmitt TH, Gultekin T, Caspary WF, Wehrmann T. Sedation with propofol plus midazolam versus propofol alone for interventional endoscopic procedures: a prospective, randomized study. Aliment Pharmacol Ther. 2000;14:1207-1214.

34. Sipe BW, Rex DK, Latinovich D, et al. Propofol versus midazolam/meperidine for outpatient colonoscopy: administration by nurses supervised by endoscopists. Gastrointest Endosc. 2002;55: $815-825$.

35. Vargo JJ, Holub JL, Faigel DO, Lieberman DA, Eisen GM. Risk factors for cardiopulmonary events during propofol-mediated upper endoscopy and colonoscopy. Aliment Pharmacol Ther. 2006;24:955-963. 